\title{
Comunicação
}

[Communication]

\section{Produção e composição bromatológica de vinte e cinco genótipos de sorgo (Sorghum bicolor (L.) Moench)}

[Chemical composition and production of 25 hybrids of sorghum (Sorghum bicolor (L.) Moench)]

\author{
R.T. Magalhães ${ }^{1}$, L.C. Gonçalves ${ }^{2}$, I. Borges ${ }^{2}$, J.A.S. Rodrigues ${ }^{3}$, J.F. Fonseca ${ }^{4}$ \\ ${ }^{1}$ Departamento de Zootecnia - UCG \\ Av. Universitária, 1069 \\ Caixa Postal 86 \\ 74605-010 - Goiânia, GO \\ ${ }^{2}$ Escola de Veterinária - UFMG - Belo Horizonte, MG \\ ${ }^{3}$ Embrapa Milho e Sorgo - Sete Lagoas, MG \\ ${ }^{4}$ Zootecnista autônomo - Goiânia, GO
}

A cultura do sorgo (Sorghum bicolor (L.) Moench) tem se mostrado como alternativa viável para a produção de silagem, sobretudo em regiões onde a reduzida disponibilidade de água ou a distribuição irregular das chuvas constituem fatores limitantes ao cultivo de outros cereais (Zago, 1991). Diversos fatores favorecem o cultivo do sorgo para produção de silagem em regiões tropicais, dentre eles destaca-se o alto potencial de produção de massa seca, tolerância à seca, a qual minimiza as perdas de produção durante períodos de estiagens, e adaptabilidade ao plantio após o corte da cultura de verão (Pedreira et al., 2003).

Estudos de comparação entre híbridos são importantes para contribuir com os programas de melhoramento genético e para recomendar aos produtores os híbridos ou cultivares cujas silagens tenham a melhor relação produção/valor nutritivo (Antunes et al., 2007). Para Zago (1991), um programa de melhoramento de sorgo deve também orientar-se no sentido de determinar características herdáveis que estejam relacionadas com a fermentação adequada e baixas perdas de matéria seca (MS) durante a ensilagem, assim como com a digestibilidade, o consumo de forragem e o desempenho animal, além de considerar algumas características como relação colmo/folha/panícula, suculência e teor de açucar do colmo, cerosidade e tanino.
A estimativa do valor nutritivo das forrageiras é importante, seja para permitir adequado manejo alimentar de dietas à base de volumosos ou para orientar no melhoramento ou na seleção de forrageiras. Os híbridos de sorgo de porte médio e de duplo propósito apresentam, normalmente, menor produção de MS por hectare do que os de porte alto. Produções de 11 a 13, de 13 a 16 e maiores que 16 toneladas por hectare $(\mathrm{t} / \mathrm{ha}) \mathrm{de}$ MS, com proporções de panículas próximas de $40 \%, 30 \%$ e $<20 \%$, são comuns, respectivamente, para sorgos de porte baixo, médio e alto, com as devidas variações de acordo com a época de plantio, fertilidade do solo, condições climáticas, densidade de plantas por área, entre outros fatores (Zago, 1991; Demarchi, 1995).

Os teores de proteína bruta (PB), das plantas de sorgo podem variar bastante, atingindo valores de 2,5 a 13,6\% (Gaggiotti et al., 1992). Essas variações, segundo Gontijo Neto et al. (2002), são atribuídas a fatores como cultivares, estádios de maturação e adubação, entre outros. Segundo Van Soest (1994), existe alta correlação negativa entre o teor de fibra em detergente neutro (FDN) e o consumo de MS pelos ruminantes. De acordo com o National Research Council (Nutrient..., 2001), a proporção ideal de FDN dietética deve ser de 25 a 35\%. Abaixo do valor mínimo, poderá haver diminuição da gordura do leite, 
perda da motilidade intestinal e aumento na incidência de acidose. $\mathrm{O}$ objetivo deste trabalho foi avaliar a produção e a composição química bromatológica de 25 genótipos de sorgo.

Foram avaliados 25 híbridos de sorgo de duplo propósito, sendo que 22 híbridos eram novos, pertencentes ao programa de melhoramento genético de sorgo da Embrapa Milho e Sorgo ATF53* 929036, ATF54*9929036, ATF53*9930022, BR007*929054, 212*9929048, CMSXS217*9929012, ATF54*9930002, ATF53*9930002, ATF53*9929024, ATF53* 9929028, CMSXS212*9929044, CMSXS212*9929024, CMSXS217*9929024, CMSXS205*9929046, CMSXS217*9929028, CMSXS212*9929028, CMSXS205*9930002, CMSXS206*9930002, CMSXS156*9930002, CMSXS157*9930002, CMSXS222*9930002, TX635*9930002 -, e três híbridos testemunhas - BR601, BR700 e VOLUMAX. Os materiais foram cultivados na Embrapa Milho e Sorgo, em Sete Lagoas-MG, no ano agrícola de 2001/2002.

O solo da área experimental foi classificado como latossolo vermelho escuro argiloso, fase cerrado, com $5 \%$ de declividade. No preparo do solo, foram realizadas uma aração e duas gradagens. Na semeadura, feita com plantadeira de parcela manual, utilizaram-se $400 \mathrm{~kg} / \mathrm{ha}$ de $\mathrm{N}: \mathrm{P}: \mathrm{K}(8: 28: 16)+0,5 \%$ Zn, e na adubação de cobertura, 40 dias após o plantio, foram usados $100 \mathrm{~kg}$ de ureia/ha. O material foi semeado em canteiros de $7 \mathrm{~m}$ de comprimento e $3,5 \mathrm{~m}$ de largura, com espaçamento entre linhas de $0,7 \mathrm{~m}$. Para o controle de plantas invasoras, aplicou-se, na fase de pré-emergência, herbicida à base de atrazina, na dosagem de $3,5 \mathrm{~L} / \mathrm{ha}$. O corte, para a amostragem, foi realizado quando os grãos se encontravam em estádio de leitoso a pastoso, em duas linhas centrais, descartando-se um metro nas extremidades dos canteiros.

As amostras foram submetidas à pré-secagem em estufa de ventilação forçada a $65^{\circ} \mathrm{C}$, por 72 horas, e processadas em moinho estacionário tipo "Willey" em peneira com malha de $1 \mathrm{~mm}$. Foram determinadas: MS a $105^{\circ} \mathrm{C}$, matéria mineral (MM) por incineração a $550^{\circ} \mathrm{C}$, PB pelo método de Kjeldhal (Official..., 1995) e os teores de FDN e FDA segundo a metodologia descrita por Van Soest et al. (1991). Utilizou-se o delineamento experimental de blocos ao acaso, com três repetições por tratamento (híbrido). Os dados obtidos foram submetidos à análise de variância, e, para a comparação de médias, utilizou-se o teste de Scott-Knot a 5\% de probabilidade.

Os resultados de produção de matéria seca (PMS), em t/ha e das análises químicas bromatológicas da fração planta inteira, na forma in natura, dos 25 genótipos de sorgo são apresentados na Tab. 1.

O genótipo VOLUMAX apresentou a maior PMS $(16,08 \mathrm{t} / \mathrm{ha})$, diferindo dos demais $(\mathrm{P}<0.05)$. Os sorgos CMSXS212*9929044 e ATF54*9930002 tiveram produção intermediária, com 11,54 e 11,70t/ha, respectivamente. As menores produtividades de MS (7,47 e 7,85t/ha) foram obtidas pelos genótipos TX635*9930002 e CMSXS 212*9929024, as quais não diferiram entre si $(\mathrm{P}>0,05)$. Os resultados mais elevados e intermediários obtidos para PMS estão próximos aos valores citados por Pedreira et al. (2003), que, ao trabalharem com diferentes híbridos forrageiros, observaram PMS que variaram de 16,03 a 10,8t/ha. As menores produtividades estão dentro dos parâmetros observados por Gomes et al. (2006), que encontraram valores entre 6,88 e 14,83t/ha. As variações encontradas nas produtividades da MS dos genótipos estudados neste experimento podem ser explicadas pelas suas diferentes características morfológicas e qualitativas.

De acordo com os percentuais de MS, mostrados na Tab. 1, os genótipos experimentais CMSXS205*9929046, com 42,56\%, e CMSXS217*9929012, com 42,08\%, apresentaram teores superiores $(\mathrm{P}<0,05)$ em relação aos demais híbridos. Os menores teores variaram de 33,27 a $33,85 \%$. Os teores de MS, para os genótipos CMSXS156*9930002; VOLUMAX;

ATF53*9929036; BR601 e ATF54*9929036, não diferiram entre si $(\mathrm{P}>0,05)$.

O teor médio de MM não diferiu $(\mathrm{P}>0,05)$ entre os híbridos, apresentando variação de 2,83 (BR601) a 4,16\% (CMSXS217 * 9929024). Estes resultados foram semelhantes e próximos aos valores de 4,0 a $2,8 \%$ encontrados por Pedreira et al. (2003) em diferentes híbridos de sorgo. 
Tabela 1. Produtividade de matéria seca (PMS -t/ha), matéria seca (MS) matéria mineral (MM), proteína bruta (PB), fibra em detergente neutro (FDN) e fibra em detergente ácido (FDA) de 25 genótipos de sorgo

\begin{tabular}{|c|c|c|c|c|c|c|}
\hline Genótipos & $\begin{array}{l}\text { PMS } \\
\text { (t/ha) }\end{array}$ & $\begin{array}{c}\text { MS } \\
\%\end{array}$ & $\begin{array}{c}\mathrm{MM} \\
\% \\
\end{array}$ & $\begin{array}{c}\text { PB } \\
\%\end{array}$ & $\begin{array}{c}\text { FDN } \\
\%\end{array}$ & $\begin{array}{c}\text { FDA } \\
\% \\
\end{array}$ \\
\hline AFT53*9929036 & $9,68 \mathrm{~h}$ & $33,48 \mathrm{~h}$ & $3,68 \mathrm{a}$ & $5,99 \mathrm{~b}$ & $65,30 \mathrm{a}$ & $35,65 a$ \\
\hline ATF54*9929036 & $14,17 b$ & $33,85 \mathrm{~h}$ & $3,78 \mathrm{a}$ & $7,73 a$ & $68,80 \mathrm{a}$ & $35,91 \mathrm{a}$ \\
\hline ATF53*9930022 & $12,85 \mathrm{c}$ & $37,57 \mathrm{~d}$ & $3,44 \mathrm{a}$ & $6,61 b$ & $61,43 a$ & $28,48 b$ \\
\hline BR007*9929054 & $11,09 f$ & $40,10 \mathrm{c}$ & $3,81 \mathrm{a}$ & $7,27 \mathrm{a}$ & $73,30 \mathrm{a}$ & $32,65 \mathrm{a}$ \\
\hline CMSXS212*9929048 & $12,92 \mathrm{c}$ & $41,10 b$ & $3,98 \mathrm{a}$ & $7,37 \mathrm{a}$ & $65,21 \mathrm{a}$ & $28,68 b$ \\
\hline CMSXS217*9929012 & $12,50 \mathrm{~d}$ & $42,08 \mathrm{a}$ & $3,62 \mathrm{a}$ & $8,26 \mathrm{a}$ & $64,94 \mathrm{a}$ & $30,99 b$ \\
\hline ATF54*9930002 & $11,70 \mathrm{e}$ & $35,62 \mathrm{f}$ & $3,61 \mathrm{a}$ & $7,16 a$ & $62,22 \mathrm{a}$ & $30,77 b$ \\
\hline ATF53*9930002 & $9,31 \mathrm{i}$ & $35,50 f$ & $3,38 \mathrm{a}$ & $6,94 a$ & $61,50 \mathrm{a}$ & $30,90 b$ \\
\hline ATF53*9929024 & $10,96 f$ & $35,78 \mathrm{f}$ & $4,00 \mathrm{a}$ & $6,41 b$ & $64,94 a$ & $31,93 b$ \\
\hline ATF53*9929028 & $12,54 \mathrm{~d}$ & $37,56 \mathrm{~d}$ & $3,55 \mathrm{a}$ & $7,34 \mathrm{a}$ & $63,38 \mathrm{a}$ & $30,22 b$ \\
\hline CMSXS212*9929044 & $11,54 \mathrm{e}$ & $40,20 \mathrm{c}$ & $3,41 \mathrm{a}$ & $7,79 a$ & $64,48 \mathrm{a}$ & $31,38 b$ \\
\hline CMSXS212*9929024 & $7,85 \mathrm{j}$ & $39,55 \mathrm{c}$ & $3,41 \mathrm{a}$ & $6,33 b$ & $65,19 a$ & $33,55 \mathrm{a}$ \\
\hline CMSXS217*9929024 & $9,65 \mathrm{~h}$ & $39,55 \mathrm{c}$ & $4,16 a$ & $7,08 \mathrm{a}$ & $59,77 \mathrm{a}$ & $29,36 b$ \\
\hline CMSXS205*9929046 & $13,14 \mathrm{c}$ & $42,56 \mathrm{a}$ & $3,73 \mathrm{a}$ & $6,25 b$ & $63,78 \mathrm{a}$ & $33,34 \mathrm{a}$ \\
\hline CMSXS217*9929028 & $10,93 f$ & $37,72 \mathrm{~d}$ & $3,74 a$ & $6,65 b$ & $65,41 \mathrm{a}$ & $32,83 \mathrm{a}$ \\
\hline CMSXS212*9929028 & $10,41 \mathrm{~g}$ & $40,29 c$ & $3,51 \mathrm{a}$ & $7,12 \mathrm{a}$ & $59,92 \mathrm{a}$ & $28,98 b$ \\
\hline CMSXS205*9930002 & $12,94 \mathrm{c}$ & $36,53 \mathrm{e}$ & $3,73 \mathrm{a}$ & $7,79 \mathrm{a}$ & $59,03 \mathrm{a}$ & $29,76 b$ \\
\hline CMSXS206*9930002 & $12,11 \mathrm{~d}$ & $36,63 \mathrm{e}$ & $3,67 \mathrm{a}$ & $6,09 b$ & $73,40 \mathrm{a}$ & $35,04 \mathrm{a}$ \\
\hline CMSXS156*9930002 & $10,05 \mathrm{~g}$ & $33,27 \mathrm{~h}$ & $3,13 \mathrm{a}$ & $6,65 b$ & $64,07 \mathrm{a}$ & $26,78 b$ \\
\hline CMSXS157*9930002 & $9,20 \mathrm{i}$ & $36,45 \mathrm{e}$ & $3,89 \mathrm{a}$ & $6,69 b$ & $62,53 a$ & $30,97 b$ \\
\hline CMSXS222*9930002 & $9,18 \mathrm{i}$ & $35,67 f$ & $3,67 \mathrm{a}$ & $6,15 b$ & $65,45 \mathrm{a}$ & $32,46 a$ \\
\hline TX635*9930002 & $7,47 \mathrm{j}$ & $35,76 \mathrm{f}$ & $3,54 \mathrm{a}$ & $5,24 b$ & $66,78 \mathrm{a}$ & $35,75 \mathrm{a}$ \\
\hline BR601 & $11,25 \mathrm{f}$ & $33,55 \mathrm{~h}$ & $2,83 \mathrm{a}$ & $5,96 b$ & $66,90 \mathrm{a}$ & $34,73 a$ \\
\hline BR700 & $6,87 \mathrm{k}$ & $34,71 \mathrm{~g}$ & $3,65 \mathrm{a}$ & $6,44 b$ & $67,43 a$ & $35,30 \mathrm{a}$ \\
\hline VOLUMAX & $16,08 \mathrm{a}$ & $33,45 \mathrm{~h}$ & $3,14 \mathrm{a}$ & $5,54 \mathrm{~b}$ & $67,33 \mathrm{a}$ & $33,94 \mathrm{a}$ \\
\hline $\mathrm{CV}(\%)$ & 2,45 & 1,47 & 8,96 & 12,48 & 8,77 & 9,86 \\
\hline
\end{tabular}

Médias seguidas por letras distintas na coluna diferem entre si $(\mathrm{P}>0,05)$ pelo teste de Scott-Knot.

Os genótipos

ATF53*9930002; CMSXS217*9929024;

CMSXS212*9929028; ATF54*9930002;

BR007*9929054; ATF53*9929028;

CMSXS212*9929048; ATF54*9929036;

CMSXS212*9929044; CMSXS205*9930002 e CMSXS217*9929012, com conteúdos de PB entre 6,94 e $8,26 \%$, apresentaram os maiores teores proteicos $(\mathrm{P}<0,05)$ em relação aos outros genótipos, que ficaram entre 5,24 e $6,69 \%$. A concentração de PB na MS estava, na maioria dos genótipos, acima do mínimo desejado para garantir fermentação ruminal adequada, que, segundo Van Soest (1994), é de 6,0\%. As diferenças verificadas entre as médias dos teores de PB devem-se, possivelmente, a diferentes concentrações da fração panícula na planta inteira. Gomes et al. (2006), ao avaliarem diferentes híbridos de sorgo, encontraram teores de PB que variaram de 3,3 a 6,4.
O teor de FDN é indicativo da quantidade total de fibra do volumoso e está diretamente relacionado ao consumo dos animais, e o teor de FDA se relaciona à digestibilidade do volumoso por apresentar maior proporção de lignina na fração digestível (Rosa et al., 2004). Os valores médios de FDN não apresentaram variações entre os genótipos estudados $(\mathrm{P}>0,05)$. Tendo em vista os fatores negativos dos altos teores de FDN na limitação de consumo de plantas forrageiras, o genótipo CMSXS205*9930002 apresentou o menor valor $(59,03 \%)$, e o genótipo CMSXS206*9930002 o maior $(73,40 \%)$. Os teores de FDN dos genótipos avaliados estão próximos aos relatados por Pedreira et al. (2003) e Gomes et al. (2006), que variaram entre 57,4 a $70,3 \%$ e 52,0 a67,8\%, respectivamente, e acima dos citados por Pesce et al. (2000), de 57,4 a $66,5 \%$. 
Os genótipos

CMSXS222*9930002; BR007*9929054;

CMSXS217*9929028; CMSXS205*9929046; CMSXS212*9929024; VOLUMAX; BR601; CMSXS206*9930002; BR700;

ATF53*9929036; TX635*9930002 e

ATF54*9929036, com teores de FDA entre 32,46 e $35,94 \%$, apresentaram maiores valores $(\mathrm{P}<0,05)$ em relação aos outros genótipos, que ficaram entre 26,78 e $31,93 \%$. Os teores estão dentro da faixa de 27,1 a $49,4 \%$, observada por White et al. (1988), ao avaliaram 80 cultivares de sorgo, e próximos aos valores de 25,5 a $35,9 \%$ encontrados por Pedreira et al. (2003).

De acordo com os resultados obtidos, todos os 25 híbridos analisados podem ser utilizados para produção de silagens. Destacam-se os genótipos ATF54*9929036, CMSXS212*9929048,

CMSXS217*9929012 e VOLUMAX, por apresentarem maior produtividade, elevados teores de PB e baixos teores de FDN e FDA.

Palavras-chave: sorgo, composição bromatológica, ruminante

\begin{abstract}
Chemical composition and dry matter (DM) productivity of 25 genotypes of sorghum were obtained. The experiment was carried out in a randomized block design with 25 treatments and three replications each. The data were submitted to analysis of variance and the means grouped by Scott-Knot Test (5\%). The level of DM productivity varied from 6.82 to 14.17ton/hectare, and the higher level was obtained by VOLUMAX genotype (16.09 ton/hectare). The levels of crude protein varied from 5.24 to $7.79 \%$. No differences were detected between the genotypes to neutral detergent fiber levels, which varied from 59.03 to $73.04 \%$. Considering the level of acid detergent fiber, the variation interval was 26.78 to 40.92\%. The better genotypes for silage production were ATF54*9929036, CMSXS212*9929048, CMSXS217*9929012, and VOLUMAX.
\end{abstract}

Keywords: sorghum, bromatologic composition, digestibility, ruminant

\section{REFERÊNCIAS BIBLIOGRÁFICAS}

ANTUNES, R.C.; RODRIGUEZ, N.M.; GONÇALVES, L.C. et al. Composição bromatológica e parâmetros físicos de grãos de sorgo com diferentes texturas de endosperma. Arq. Bras. Med. Vet. Zootec., v.59, p.1351-1354, 2007.

DEMARCHI, J.J.A.A.; BOIN, C.; BRAUN, G. A cultura do sorgo (Sorghum bicolor (L.) Moench) para a produção de silagens de alta qualidade. Zootecnia, v.33, p.111-136, 1995.

GAGGIOTTI, M.C.; ROMERO, L.A.; BRUNO, O.A. et al. Cultivares de sorgos forrajeros para silage. II. Características fermentativas y nutritivas de los silajes. Rev. Arg. Prod. Anim., v.12, p.163-167, 1992.

GOMES, S.O.; PITOMBEIRA, J.B.; NEIVA, J.N. et al. Comportamento agronômico e composição químico-bromatológica de cultivares de sorgo forrageiro no Estado do Ceará. Rev. Cienc. Agron., v.37, p.221-227, 2006.
GONTIJO NETO, M.M.; OBEID, J.A.; PEREIRA, O.G. et al. Híbridos de sorgo (Sorghum bicolor (L.) Moench) cultivados sob níveis crescentes de adubação. Rendimento, proteína bruta e digestibilidade in vitro. Rev. Bras. Zootec., v.31, p.293-301, 2002.

NUTRIENT requeriments of dairy cattle. 7 ed. Waschington D.C.: National academy of Sciences, 2001. 381p.

OFFICIAL methods of analysis. 16.ed. Washington, DC: AOAC, 1995. 2000p.

PEDREIRA, M.S.; REIS, R.A.; BERCHIELLI, T.T. et al. Características agrônomicas e composição química de oito híbridos de sorgo (Sorghum bicolor (L.) Moench). Rev. Bras. Zootec., v.32, p.1083-1092, 2003.

PESCE, D.M.C.; GONÇALVES, L.C.; RODRIGUES, J.A.S. et al. Análise de vinte genótipos de sorgo (Sorghum bicolor (L.) Moench) de portes médio e alto, pertencentes ao ensaio nacional. Rev. Bras. Zootec., v.29, p.978987, 2000. 
ROSA, J.R.P.; SILVA, J.H.S.; RESTLE, J. et al. Avaliação do comportamento agronômico da planta e valor nutritivo da silagem de diferentes híbridos de milho (Zea mays, L). Rev. Bras. Zootec., v.33, p.302-312, 2004.

VAN SOEST, P.J.; ROBERTSON, J.B.; LEWIS, B.A. Methods for dietary fiber, neutral, neutral detergent fiber, and non starch polysaccharides in relation to animal nutrition. J. Dairy Sci., v.74, p.3583-3597, 1991.

VAN SOEST, P.J. Nutritional ecology of the ruminant. 2.ed. Ithaca: Cornell University, 1994. 476p.
WHITE, J.; BOLSEN, K.; KIRCH, B. et al. Seleting forage sorghum cultivars for silage. Manhatan: Kansas Agricultural Experimental Station, 1988. 8p. (KSU. Report of Progress, 539)

ZAGO, C.P. Cultura de sorgo para produção de silagem de alto valor nutritivo. In: SIMPÓSIO SOBRE NUTRIÇÃO DE BOVINOS, 4., 1991, Piracicaba. Anais... Piracicaba: FEALQ, 1991. p.169-217. 